DOI: http://dx.doi.org/10.11606/issn.1984-4867.v26i4p745-773

\title{
Proposição e Validação de Escala para Mensuração de Capacidade Turística
}

Proposal and Validation of Scale for Tourist Capacity Measurement

Proposición y Validación de Escala para el Medición de la Capacidad de Turismo

Elvis Silveira-Martins ${ }^{1}$

Vinicius Costa da Silva Zonatto ${ }^{2}$

\section{Resumo}

Este estudo objetiva desenvolver e validar uma escala para a mensuração da capacidade turística das empresas que atuam neste segmento. As capacidades turísticas abordadas neste trabalho são compreendidas como a capacidade das organizações que atuam no setor turístico em gerenciar potencialidades internas da empresa com vistas a agregação de valor aos serviços prestados. Por meio destas, torna-se possível a diferenciação e o desenvolvimento de vantagens competitivas, bem como o fortalecimento destas organizações. Para tanto, pesquisa exploratória e descritiva foi realizada com 65 hotéis com foco no turismo, localizados em diferentes regiões da cidade de São Paulo. Os resultados encontrados revelaram cinco capacidades turísticas determinantes para a diferenciação competitiva destas empresas, as quais compõe o construto proposto nesta pesquisa, sendo estas: geração de atendimento personalizado ao turista; conhecimento sobre os atrativos turísticos (locais) do município e região; atenção aos novos acontecimentos turísticos (locais) no município e região; conhecimento sobre a história local e regional; e, localização próxima a pontos estratégicos. Conclui-se que a compreensão das capacidades turísticas desenvolvidas por empresas hoteleiras pode contribuir para o entendimento de fatores que favorecem a capacidade adaptativa destas empresas considerando as características do ambiente dinâmico do setor. Da mesma forma, pode fornecer evidências que permitam o entendimento de como estas empresas alcançam e sustentam vantagens competitivas, o que resulta em um novo campo de pesquisa para essa temática.

Palavras-chave: Capacidades dinâmicas; Capacidades turísticas; Empresas hoteleiras.

\begin{abstract}
This study aims to develop and validate a scale to measure the tourism capacity of companies operating in this segment. Tourist capabilities discussed in this work are understood as the capacity of organizations working in the tourism sector in managing internal potential of the company with a view to adding value to the services provided. Through these, it becomes possible to differentiate and develop competitive advantages as well as strengthening those organizations. Therefore, exploratory and descriptive research was conducted with 65 hotels

${ }^{1}$ Professor do Programa de Pós-graduação em Desenvolvimento Territorial e Sistemas Agroindustriais da Universidade Federal de Pelotas (PPGDTSA/UFPel). Doutor em Administração e Turismo pela Universidade do Vale do Itajaí. Pelotas-RS, Brasil. E-mail: elvis.professor@gmail.com

${ }^{2}$ Professor do Programa de Pós-graduação em Ciências Contábeis da Universidade Regional de Blumenau (PPGCC/FURB). Doutor em Ciências Contábeis e Administração pela Universidade Regional de Blumenau. Blumenau-SC. Brasil. E-mail: viniciuszonatto@gmail.com
\end{abstract}


focused on tourism, located in different regions of São Paulo. The results showed the five determinants tourist capacities for competitive differentiation of these companies, which make up the proposed construct in this study, which are: generation of personalized service to tourists; knowledge about the tourist attractions (local) in the city and region; attention to new tourism events (local) in the city and region; knowledge of the local and regional history; and location close to strategic points. It is concluded that the understanding of the tourist capacities developed for hotel companies can contribute to the understanding of factors that favor the adaptive capacity of these companies considering the characteristics of the dynamic environment. Similarly, can provide evidence to the understanding of how these companies achieve and sustain competitive advantages, resulting in a new field of research for this topic.

Keywords: Dynamic capabilities; Tourist capacities; Hotel companies.

\section{Resumen}

Este estudio tiene como objetivo desarrollar y validar una escala para medir la capacidad turística de las empresas que operan en este segmento. Capacidades turísticos analizados en este trabajo se entiende como la capacidad de las organizaciones que trabajan en el sector turístico de la gestión del potencial interno de la empresa con el objetivo de agregar valor a los servicios prestados. A través de ellas, se hace posible diferenciar y desarrollar ventajas competitivas, así como el fortalecimiento de esas organizaciones. Por lo tanto, la investigación exploratoria y descriptiva se realizó con 65 hoteles enfocados en el turismo, que se encuentra en diferentes regiones de São Paulo. Los resultados mostraron los cinco determinantes capacidades turísticas para la diferenciación competitiva de estas empresas, que conforman el construto propuesto en este estudio, que son: generación de un servicio personalizado a los turistas; conocimiento sobre los lugares de interés turístico (locales) en la ciudad y la región; atención a los nuevos eventos de turismo (local) en la ciudad y la región; conocimiento de la historia local y regional; y la ubicación cerca de los puntos estratégicos. Se concluye que la comprensión de las capacidades turísticas desarrolladas por empresas hoteleras puede contribuir a la comprensión de los factores que favorecen la capacidad de adaptación de estas empresas que están considerando las características del entorno de la industria dinámica. Del mismo modo, puede proporcionar evidencia a la comprensión de cómo estas empresas a alcanzar y mantener ventajas competitivas, lo que resulta en un nuevo campo de investigación para este tema.

Palabras-clave: Capacidades dinâmicas; Capacidades turísticas; Las compañías hoteleras.

\section{Introdução}

A atividade turística tem se destacado na economia global (KASIM, 2006; JIANG; SU; DU; 2013; MONDO; FIATES, 2015) como uma importante fonte de geração de emprego e renda, que estimula o comércio internacional (RAMGULAM; RAGHUNANDAN; RAGHUNANDAN, 2012), o desenvolvimento da economia e o crescimento do produto interno bruto dos Países 
(PIB) (BOOYEN, 2012). O turismo agrega valor econômico e uma vez bem gerido apoia o desenvolvimento local.

Diversas empresas atuam neste contexto, explorando as questões turísticas como uma oportunidade de negócios, como agências de viagens, empresas de transporte, alimentação e organizações hoteleiras. O segmento hoteleiro é um dos principais atores envolvidos neste processo, uma vez que ele relaciona-se diretamente com os indivíduos que buscam no turismo uma oportunidade para negócios, descanso ou lazer.

As experiências vividas pelos turistas determinam seu nível de satisfação com os serviços prestados. As necessidades de hospedagem e alimentação afetam diretamente a satisfação dos usuários dos serviços hoteleiros. Logo, o desenvolvimento de capacidades pode torna-se um atrativo para estas empresas, com vistas a atender as necessidades dos clientes, retendo-os e fidelizando, para que estes possam retornar e divulgar os serviços prestados pela empresa, o que agrega valor à organização. Conforme explicam Pezzi e Vianna (2015), a experiência está relacionada com a diferenciação em relação a concorrência, possibilitando uma maior valorização do consumidor em relação a oferta e, desta forma, amenizando a importância do preço a ser pago.

Neste sentido, as capacidades dinâmicas assumem um importante papel no processo de gestão estratégica destas organizações (TEECE; PISANO, 1994). As capacidades dinâmicas se referem a capacidade da firma em inovar e reagir melhor que seus concorrentes (COLLIS, 1994; TEECE; PISANO; SHUEN, 1997; DOSI; NELSON; WINTER, 2000; TEECE, 2009). Estão relacionadas às ações desenvolvidas pela empresa com vistas a desenvolver-se e diferenciar-se dos concorrentes, pela qualidade dos serviços prestados e seus diferenciais competitivos. De acordo com Mondo e Fiates (2015, p. 114), a qualidade de serviços turísticos é entendida "como pressuposto da percepção de satisfação e, auxilia juntamente com outras variáveis na criação da imagem do atrativo ou destino turístico".

Entende-se que o turismo pode proporcionar as empresas hoteleiras o desenvolvimento de capacidades específicas, denominadas neste estudo como capacidades turísticas. As capacidades turísticas referem-se a capacidade das organizações que atuam no setor turístico em gerenciar potencialidades internas da empresa com vistas a agregação de valor aos serviços prestados. Por meio destas, torna-se possível a diferenciação e o desenvolvimento de vantagens competitivas, bem como o fortalecimento destas organizações. 
O desenvolvimento de capacidades turísticas pode agregar valor as organizações, auxiliando o desenvolvimento de recursos estratégicos e a obtenção de vantagens competitivas sustentáveis. Apesar da sua importância, poucos estudos dedicam-se a investigar o desenvolvimento de capacidades dinâmicas nas organizações. Especificamente no setor turístico, considerando as especificidades das empresas hoteleiras, o desenvolvimento de capacidades turísticas permanece pouco investigado, o que se apresenta como uma lacuna teórica de pesquisa para a realização de novos estudos.

Compreender o desenvolvimento de capacidades turísticas em empresas hoteleiras pode contribuir para o entendimento de fatores que favorecem o desenvolvimento destas organizações, bem como seu impacto sobre o desempenho dessas empresas. Da mesma forma, permite avaliar como estas organizações utilizam informações turísticas do contexto em que estão inseridas, como um mecanismo para o desenvolvimento de suas capacidades dinâmicas.

Neste contexto, torna-se oportuno investigar "quais capacidades turísticas podem ser desenvolvidas por empresas hoteleiras que atuam com ênfase no turismo", a fim de se identificar um construto adequado que permita avaliar a mensuração para tais capacidades em outras empresas que atuam no setor. A identificação de uma escala para a mensuração das capacidades turísticas permitirá a realização de novos estudos, avaliando as relações existentes entre tais capacidades e outras variáveis, como por exemplo o desempenho destas empresas.

Valendo-se destes pressupostos, o objetivo central desta pesquisa é desenvolver e validar uma escala para a mensuração da capacidade turística das empresas que atuam neste segmento. Esta pesquisa procura ampliar de maneira inovadora os horizontes sobre as temáticas relacionadas a estratégia, mudanças organizacionais e vantagens competitivas, possibilitando novos prismas de análise, bem como contribuir para a melhoria dos processos de gestão das empresas que atuam neste setor, compreendendo o desenvolvimento de capacidades turísticas em empresas hoteleiras. Nesta perspectiva, o estudo justifica-se pela relevância do tema e escassez de estudos com esta abordagem. A compreensão das capacidades turísticas desenvolvidas por empresas hoteleiras pode contribuir para o entendimento de fatores que favorecem a capacidade adaptativa destas empresas, considerando as características do ambiente dinâmico do setor. Da mesma forma, pode fornecer evidências que permitam o entendimento de como estas empresas alcançam e sustentam vantagens competitivas, o que resulta em um novo campo de pesquisa para essa temática. 
Outro aspecto que justifica o desenvolvimento desta pesquisa é o cenário competitivo vivenciado pelo setor hoteleiro, em que os tomadores de decisões necessitam de ferramentas eficazes para suas ações, sob pena de insucesso gerencial. De acordo com Meira e Anjos (2014), a gestão dos processos gerenciais dos hotéis passou a ter um papel crucial na manutenção da organização no mercado, por conta da entrada das redes hoteleiras internacionais no mercado nacional, o que gerou aumento concorrencial.

Ademais, não foram encontradas outras pesquisas com este escopo (validação de escala de capacidade turística) e âmbito (setor hoteleiro), reforçando a singularidade da pesquisa e, portanto, a sua contribuição com a aproximação de uma nova perspectiva teórica/empírica com ciência do turismo, área de justificativa pelo desenvolvimento da mesma.

No que se refere a perspectiva teórica, Silveira-Martins e Tavares (2014) informam que são encontradas nas literaturas de capacidades dinâmicas, capacidades gerenciais, mercadológicas e tecnológicas, o que excluí as capacidades (turísticas) investigadas nesta pesquisa, específicas a temática objeto de estudo (turismo). Martins et al. (2014) reconhecem ainda a existência da capacidade ambidestra, e Escobar (2012) a capacidade de absorção e de inovação. Assim, as capacidades turísticas constituem-se uma lacuna teórica que explora uma necessidade específica para o segmento turístico, como recomenda Teece, Pisano e Shuen (1997), quando destaca a especificidade da teoria das capacidades dinâmicas.

Este artigo está organizado em cinco seções, além desta introdução. A primeira parte explora a constituição, desenvolvimento e a consolidação da capacidade dinâmica, turismo e capacidade turística. Na segunda seção, apresenta-se o quadro teórico de referência que procura situar o contexto científico do estudo. Na sequência, aborda-se a metodologia que orientou a condução do estudo sob análise. Na quarta seção, discute-se e pondera-se sobre a análise dos dados das empresas pesquisadas e, na última seção, apresenta-se a conclusão, tecendo-se reflexões e novas direções, além de possibilidades para estudos sobre a capacidade turística.

\section{Marco Teórico}

Nesta seção apresenta-se a fundamentação teórica do estudo. Incialmente são apresentados alguns conceitos que cercam os construtos turismo e capacidade dinâmica. A seguir, procura-se desenvolver o conceito para o construto capacidade turística, tema central proposto nesta pesquisa. 


\subsection{Turismo}

O impacto do turismo na economia global é significativo (JIANG; SU; DU; 2013; MONDO; FIATES, 2015). Sendo um fenômeno mundial, o turismo tornou-se um dos setores que mais cresce na economia global (KASIM, 2006). Para Jiang, Su e Du (2013), o turismo é um fenômeno complexo que abrange diferentes variáveis: sociedade, economia e meio ambiente. A indústria do turismo é uma das indústrias de mais rápido crescimento a nível internacional. $\mathrm{O}$ turismo contribui para o produto interno bruto (PIB), diversifica a economia local e cria oportunidades de negócios, contribuindo para a base tributária local (BOOYEN, 2012; RAMGULAM; RAGHUNANDAN; RAGHUNANDAN, 2012).

De acordo com a Organização Mundial do Turismo (OMT) o turismo continuou a ganhar força em 2013, com o aumento do apoio e reconhecimento da relevância do setor para a esfera socioeconômica e o desenvolvimento mundial. Todavia, os destinos turísticos e empresas necessitam evoluir continuamente, a fim de adaptarem-se a um mercado cada vez mais disputado e com constantes incertezas (OMT, 2014).

Conforme explicam Cosmina-Simona et al. (2013), o turismo é ponderado como um mecanismo real da economia, por representar fonte importante para o bem-estar da população das áreas que são menos desenvolvidas a partir do ponto de vista econômico. O turismo é a força que envolve o natural do potencial humano e cultural. No entanto, segundo os autores, este é possível apenas mediante a participação dos principais atores que têm papel na produção, promoção e desenvolvimento do mesmo.

Para Roxana, Anamaria e Corina (2013), o setor hoteleiro não fica distante deste cenário. No entender dos pesquisadores, para competir neste segmento cada vez mais turbulento, instável e globalizado, os gestores de hotéis têm de considerar a diferenciação como uma necessidade. Entende-se esta diferenciação em termos de serviços inovadores e/ou personalizados, recursos humanos qualificados, valor da marca, responsabilidade social, implementação da informação e tecnologia da informação, e orientação gerencial pró-ativa em relação ao cliente (ZONATTO; SCHUH; ZONATTO, 2014).

Kirovska (2011) defende que o desenvolvimento do turismo é determinado pelo direcionamento e práticas da sua gestão estratégica. A gestão estratégica, segundo o autor, é um processo próativo que almeja a compatibilidade de longo prazo do campo correspondente em um ambiente de turismo que fora planejado. Com o aumento da concorrência e dinâmicas ambientais, o 
desenvolvimento do turismo, sem um posicionamento estratégico coerente, passa a gerar incertezas (MEIRA; ANJOS, 2014). Segundo Kirovska (2011), o desenvolvimento do turismo está atrelado diretamente as atividades empresariais (diversas), sendo que o estreitamento das relações entre as duas atividades econômicas gerará lastro para a manutenção dos negócios (turismo e comércios).

Uma estratégia utilizada por empresas hoteleiras para o fortalecimento de suas capacidades é por meio da formação de alianças estratégicas (ZONATTO; SCHUH; ZONATTO, 2014). As alianças estratégicas estabelecidas no setor turístico compreendem todas as parcerias e relacionamentos relevantes estabelecidos pelas empresas que atuam neste setor, com clientes, fornecedores, complementors, concorrentes, entidades governamentais e organizações representativas do setor/indústria (BRUNELLI; MACEDO-SOARES, 2012). No entanto, segundo Pansiri (2009), antes dos gestores formarem alianças estratégicas, estes devem realizar uma análise ambiental, tendo em vista a compreensão de como fatores internos e externos afetam as empresas que atuam no turismo.

Além da monitoração dos ambientes interno e externo, outros fatores podem impactar repentinamente nas atividades desenvolvidas por empresas que atuam no setor turístico, como por exemplo as mudanças climáticas (meio ambiente) (MOLNAR; STANCIULESCU, 2011). De acordo com os autores, estas variações influenciam diretamente os negócios da indústria do turismo, especialmente os direcionados aos empreendimentos localizados em regiões quentes (praias) ou frias (estações de esqui).

Desta maneira, observa-se que o processo de gestão de empreendimentos turísticos torna-se dinâmico, complexo e sistêmico (MEIRA; ANJOS, 2014). Por esta razão, torna-se importante abordar o turismo como uma atividade que faz parte do modo de vida atual, devido a um conjunto de fatores como: a mudança do perfil dessa sociedade e do meio ambiente; as mudanças nas formas de trabalho; e as mudanças relacionadas com a cultura, uma vez que o homem vive em sociedade e esta é a base para que surja cultura (MENEZES, 2004).

Embora o turismo possa ser configurado como uma ferramenta eficaz para o desenvolvimento econômico, esta prática possui limitações em países menos desenvolvidos, que não recebem quantidade significativa de fluxos turísticos (GARCÍA, 2012). Isso ocorre porque os países desenvolvidos têm alguns fatores que favorecem o turismo, que não estão presentes nos países menos desenvolvidos. Em contraponto, González (2013) destaca que dentre os stakeholders, os 
residentes nas regiões têm se convertido em agentes essenciais para alavancagem do desenvolvimento e gestão do turismo, o que pode contribuir para a mudança deste cenário. Neste contexto, um aspecto que pode estimular as atividades turísticas em qualquer ambiente, refere-se ao desenvolvimento de capacidades dinâmicas.

\subsection{Capacidade dinâmica}

A teoria que sustenta o conceito de capacidades dinâmicas estrutura-se na premissa de que as empresas estão envoltas em um contexto Shumpeteriano e evolutivo. Desta maneira, o fato de uma empresa produzir um conjunto de produtos e serviços não significa que a mesma terá o seu empreendimento sustentado por muito tempo. Assim, para obter êxito as organizações, por qualquer tempo, deverão investir em inovação. Portanto, a concentração dos esforços na capacidade de inovação (capacidade dinâmica) será preditora de desempenho organizacional (NELSON, 1991).

No entender de Teece e Pisano (1994) as capacidades dinâmicas são fontes de vantagem competitiva, por conta de enfatizarem dois aspectos fundamentais que não eram incorporados no núcleo central de perspectivas estratégicas anteriores: capacidades e dinâmicas. De acordo com os autores, a capacidade destaca o papel fundamental da gestão estratégica da organização em adaptar, integrar e re-configurar recursos e competências funcionais para as volatilidades do ambiente. Já o termo dinâmico relaciona-se com as respostas estratégicas necessárias ao mercado com limitadores temporais, além da aceleração do ritmo com vistas a inovação e a natureza da concorrência futura e os mercados que possuem dificuldade de previsibilidade.

A teoria das capacidades dinâmicas emerge como uma evolução da visão baseada em recursos que, segundo Teece, Pisano e Shuen (1997), possui o poder explicativo dos mecanismos, de maneira individual, que permitem às organizações obterem vantagem competitiva sustentada. Desta maneira, as capacidades dinâmicas destacam a exploração de competências específicas da empresa (internas e externas) com a intenção de enfrentar as mudanças ambientais. De acordo com Maranhão e Teixeira (2015, p. 121), as capacidades dinâmicas "estão diretamente relacionadas ao sucesso organizacional, visto que representam capacidades estratégicas de alto nível, responsáveis pela articulação, reestruturação e criação de processos e rotinas organizacionais".

Nesta perspectiva, Eisenhardt e Martin (2000) procuraram identificar as diferentes correntes teóricas existentes sobre capacidades dinâmicas, agrupando-as em seis categorias, sendo estas: 
definição, heterogeneidade, padrão, resultado, vantagem competitiva e evolução. Os autores ainda contrastaram a visão tradicional destas teorias com a visão contemporânea das capacidades dinâmicas. O detalhamento dos apontamentos dos pesquisadores pode ser observado no Quadro1.

Quadro 1 - Contraste dos conceitos de capacidade dinâmica

\begin{tabular}{|c|l|l|}
\hline CATEGORIA & \multicolumn{1}{|c|}{ VISÃO TRADICIONAL } & \multicolumn{1}{c|}{ VISÃO CONTEMPORÂNEA } \\
\hline Definição & Rotinas de aprendizado de rotinas. & $\begin{array}{l}\text { Processos organizacionais e estratégicos } \\
\text { específicos (por exemplo, inovação de produtos, } \\
\text { tomada de decisões estratégicas e alianças) pelo } \\
\text { qual os gestores alteram sua base de recursos. }\end{array}$ \\
\hline Heterogeneidade & $\begin{array}{l}\text { Idiossincrático (com especificações para } \\
\text { a empresa). }\end{array}$ & $\begin{array}{l}\text { Comunalidades (melhores práticas) com alguns } \\
\text { detalhes idiossincráticos. }\end{array}$ \\
\hline Padrão & Detalhado, rotinas analíticas. & $\begin{array}{l}\text { Dependendo do dinamismo do mercado, desde } \\
\text { detalhado a rotinas analíticas simples, } \\
\text { experiencial. }\end{array}$ \\
\hline Resultado & Previsível. & $\begin{array}{l}\text { Dependendo do dinamismo do mercado, } \\
\text { previsivo ou não. }\end{array}$ \\
\hline Competitiva & $\begin{array}{l}\text { Vantagem competitiva sustentável da } \\
\text { capacidade dinâmica VRIO. }\end{array}$ & $\begin{array}{l}\text { Vantagem competitiva de valor, raridade, } \\
\text { inimitabilidade, originalidade e capacidades } \\
\text { dinâmicas fundidas. }\end{array}$ \\
\hline Evolução & Único caminho. & $\begin{array}{l}\text { Unico caminho moldado por mecanismos de } \\
\text { aprendizado, como a prática, codificações, erros e } \\
\text { estímulos. }\end{array}$ \\
\hline
\end{tabular}

Fonte: Eisenhardt e Martin (2000, p. 1111)

A detenção e emprego das capacidades dinâmicas fornece as organizações a possibilidade de resultados superiores aos concorrentes no longo prazo. Este apontamento é complementado por Augier e Teece (2009), destacando que quando as empresas são dinamicamente competitivas, a gestão estará ativa, aproveitando da melhor maneira possível as oportunidades ambientais. Neste contexto, segundo os autores, caberá aos gestores a capacidade de orquestrar os seus ativos não negociáveis, de modo que eles sejam melhor aproveitados e capturados em economias coespecializadas.

Teece e Abdulrahman (2013) no intento de distinguir as capacidades dinâmicas de capacidades comuns caracterizam esta última como sendo a ação do tomador de decisões na realização das atividades de maneira direita. Assim, as capacidades comuns envolvem esforços para otimizar o processo dentro de certos limites fixos. Já as capacidades dinâmicas relacionam-se com as atividades certas. Esta postura requer a avaliação tecnológica e empresarial das oportunidades, previsão do ambiente de negócios para ajustamento do desenho organizacional, quando necessário, e ação no momento certo. 
Conforme explicam os autores, a capacidade de implantar, ou reimplantar, os recursos em alinhamento com as necessidades complementares dos ativos é prática fundamental para a diferenciação competitiva das empresas. Desta maneira, o bom julgamento e conhecimento profundo da equipe de gestão é peça chave para as capacidades dinâmicas. Portanto, saber extrair do ambiente recursos que podem contribuir para com o desenvolvimento das capacidades dinâmicas de uma empresa pode assegurar o seu fortalecimento e sua diferenciação competitiva.

\subsection{Capacidade turística}

Neste contexto, baseando-se no pressuposto que capacidade dinâmica é entendida como a força interna da organização para se proteger, manter e antecipar as volatilidades ambientais (externas) (COLLIS, 1994; TEECE; PISANO; SHUEN, 1997; DOSI; NELSON; WINTER, 2000; TEECE, 2009), depreende-se que a capacidade turística apresenta-se como a gestão das potencialidades internas da empresa em prol do desenvolvimento das ações de turismo, antecedendo-se as ameaças ambientais e melhor administrando as oportunidades que lhe são apresentadas, gerando assim, melhores resultados organizacionais.

Trata-se da capacidade das organizações que atuam no setor turístico em gerenciar potencialidades internas da empresa, oportunizando aprendizagem, agregação de valor aos serviços prestados e o desenvolvimento de vantagem competitiva. A diferenciação competitiva por meio do desenvolvimento de capacidades turísticas tende a impactar positivamente nas atividades desenvolvidas pelas empresas que atuam neste setor, o conjunto de serviços desenvolvidos por estas organizações e seu desempenho.

No entender de Andrade, Gomes e Xavier (2010) o turismo é uma atividade de consumo, em que a prestação de serviços é fator preponderante para quem consome, sendo que a hospitalidade é algo esperado em qualquer atendimento. Neste sentido, Mota e Maciel Filho (2011) asseguram que as empresas relacionadas as atividades turísticas precisam oferecer serviços adequados com as reais necessidades de seus clientes e ofertar um produto ideal personalizado para cada perfil de cliente.

Nesta perspectiva, entende-se que uma capacidade turística que pode ser desenvolvida pelas empresas refere-se à "geração de atendimento personalizado ao turista”. O reconhecimento das especificidades dos diferentes perfis de clientes auxilia a organização no desenvolvimento de ações personalizadas, capazes de oportunizar um atendimento mais adequado às expectativas e necessidades dos clientes, o que diferenciará os serviços prestados pela organização de outros 
serviços não personalizados prestados pelos concorrentes. De acordo com Kirsten e Rogerson (2002) para uma empresa de turismo (ou nação) ser bem-sucedida neste setor, é essencial que o produto turístico seja diversificado e diferenciado de seus concorrentes.

Outra capacidade turística a ser desenvolvida pelas empresas que atuam neste setor refere-se ao "conhecimento sobre os atrativos turísticos (locais) do município e região". Conforme explicam Lundie, Dwyer e Forsyth (2007), diferentes tipos de turistas podem gerar diferentes impactos sobre os destinos (econômico, social e ambiental). Esses impactos, ou marcas, variam de acordo com mercado e segmentos, dependendo também do mix de serviços utilizados pelo turista. Tendo em vista as diferentes demandas identificadas entre os turistas, conhecer adequadamente os atrativos turísticos de determinado local, município ou região contribui para um melhor direcionamento do turista aos destinos desejados, o que contribui para o atendimento de suas expectativas e a melhoria dos seus níveis de satisfação.

No entender de Crouch e Ritchie (1999), o sucesso de um destino turístico está alicerçado na garantia de atratividade e integridade das experiências que são proporcionadas aos turistas, devendo estas, serem igual ou superar as muitas experiências alternativas de destino aberto aos visitantes potenciais. Segundo Booyen (2012), a indústria do turismo é caracterizada por pertencer a um segmento baseada no consumo de informação intensiva.

Portanto, a "atenção aos novos acontecimentos turísticos (locais) no município e região" é fundamental para que se possa encantar o turista, oferecendo a esse as informações necessárias para o alcance de suas expectativas. A qualidade informacional constitui-se um diferencial competitivo, uma vez que a informação precisa e qualificada atende as necessidades informacionais, satisfazendo o usuário da informação turística.

De maneira geral, a atividade turística ampara-se na capacidade de uma empresa reconhecer $e$ proporcionar aos turistas, atrativos e potencialidades naturais e culturais de um dado lugar, bem como proporcionar aos indivíduos alternativas de viagens, de deslocamentos para outros lugares, cujos atrativos podem estar manifestados tanto do ponto de vista dos recursos naturais quanto culturais em sua plenitude (FERREIRA, 2011). Assim sendo, um fator que pode estimular o mercado turístico em determinada região refere-se a carga histórica e cultural do destino turístico.

Deste modo, o "conhecimento sobre a história local e regional" constitui-se outra capacidade turística que pode diferenciar competitivamente os serviços prestados pelas empresas que atuam 
neste setor. Conforme explicam Perinotto e Santos (2011), a curiosidade do turista por um fato que ocorreu em determinado lugar é um dos fatores que motiva a prática do turismo. Da mesma forma, o status social percebido em relação a determinando ambiente estimula desejos pessoais do turista no simples fato de relatar a sua passagem pelo local de prestígio (PERINOTTO; SANTOS, 2011), o que também estimula o turismo. Logo, manter a organização competitiva significa mantê-la ajustada ao seu ambiente, especialmente às necessidades e desejos do seu público-alvo (OLIVEIRA; CAMPOMAR; LUIS, 2008).

Adicionalmente, entende-se que a “localização próxima a pontos estratégicos” também pode contribuir para a diferenciação competitiva das empresas que atuam no turismo, favorecendo o desenvolvimento de suas capacidades turísticas. O posicionamento geográfico (BEZERRA, 2006; GODINHO; OLIVEIRA, 2010) e a infraestrutura turística (GOH, 2012; IVARS I BAIDAL; SÁNCHEZ; REBOLLO, 2013; PIMENTEL; CARVALHO, 2014) estimulam o desenvolvimento do turismo local, favorecendo o mesmo. Por consequência, torna-se possível as empresas que atuam neste ambiente obter vantagem competitiva a partir de tais condições.

Diante do exposto, depreende-se que cinco variáveis concorrem para formar as capacidades turísticas e, por conseguinte, são determinantes básicos para a diferenciação competitiva de empresas que atuam neste setor. Estas variáveis podem ser segmentadas em: i) geração de atendimento personalizado ao turista; ii) conhecimento sobre os atrativos turísticos (locais) do município e região; iii) atenção aos novos acontecimentos turísticos (locais) no município e região; iv) conhecimento sobre a história local e regional; e, v) localização próxima a pontos estratégicos. O Quadro 2 evidencia uma síntese destas capacidades.

Quadro 2 - Capacidades turísticas propostas nesta pesquisa

\begin{tabular}{|c|c|c|}
\hline \multirow{3}{*}{ 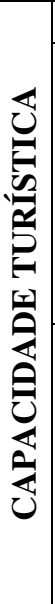 } & Variável & Descrição \\
\hline & $\begin{array}{l}\text { Geração de atendimento } \\
\text { personalizado ao turista }\end{array}$ & $\begin{array}{l}\text { Esta variável está associada com uma relação empática, prestativa e atenciosa } \\
\text { com o turista, provendo atendimento individualizado e segmentado de acordo com } \\
\text { suas necessidades. Incluem-se nesta variável, entre outros aspectos, o atendimento } \\
\text { as necessidades específicas de idosos, condições de acesso para pessoas com } \\
\text { deficiência física e/ou com mobilidade reduzida, integração entre hóspedes e } \\
\text { animais de estimação, atendimento com fluência em diferentes idiomas falados e } \\
\text { escritos. }\end{array}$ \\
\hline & $\begin{array}{c}\text { Conhecimento sobre os } \\
\text { atrativos turísticos } \\
\text { (locais) do município e } \\
\text { região }\end{array}$ & $\begin{array}{l}\text { A identificação de roteiros atrativos as diferentes demandas de turistas associam- } \\
\text { se a esta variável. Para tanto, os gestores devem estar atentos e prover uma } \\
\text { variedade de opções presentes na localidade da organização e no seu entorno } \\
\text { geográfico. Como por exemplo, pontos históricos, gastronômicos, lojas, belezas } \\
\text { naturais (parques naturais, praias, montanhas), atrativos culturais } \\
\text { (história/artes/museus), de diversão/entretenimento (p. ex. festas populares, } \\
\text { eventos esportivos), lazer em geral e centros comerciais/negócios. }\end{array}$ \\
\hline
\end{tabular}




\begin{tabular}{|c|c|c|}
\hline \multirow{3}{*}{ 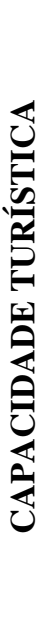 } & $\begin{array}{l}\text { Atenção aos novos } \\
\text { acontecimentos } \\
\text { turísticos (locais) no } \\
\text { município e região }\end{array}$ & $\begin{array}{l}\text { Os aspectos que caracterizam esta variável estão intrinsecamente ligados a } \\
\text { história recente da localidade e sua circunvizinhança. Entre os indicadores } \\
\text { incluem-se o conhecimento sobre novas opções de lazer/entretenimento, como } \\
\text { shows, exposições, eventos temáticos, esportivos, feiras de negócios. }\end{array}$ \\
\hline & $\begin{array}{l}\text { Conhecimento sobre a } \\
\text { história local e regional }\end{array}$ & $\begin{array}{l}\text { A história local e regional perpetuada no decorrer dos anos sustenta esta variável. } \\
\text { Desta forma, as informações turísticas devem contemplar fatos acontecidos, } \\
\text { respeitando a simetria entre qualidade quantidade das mesmas, além de } \\
\text { reconhecer o legado cultural da localidade/região. A título de exemplo incluem-se } \\
\text { nesta variável, informações sobre colonização, personalidades, cultura, arte, } \\
\text { tradições, costumes, economia. }\end{array}$ \\
\hline & $\begin{array}{l}\text { Localização próxima a } \\
\text { pontos estratégicos }\end{array}$ & $\begin{array}{l}\text { Esta variável aborda aspectos relacionados com o posicionamento geográfico da } \\
\text { organização e a infraestrutura turística. Neste sentido, devem ser apreciadas } \\
\text { informações relativas a segurança dos turistas, transporte público/deslocamentos } \\
\text { locais e regionais, proximidade com assistência médica, bares/restaurantes, } \\
\text { aeroporto. Além destes aspectos outros relacionados a infraestrutura também } \\
\text { estão associados, tais como: limpeza e preservação. }\end{array}$ \\
\hline
\end{tabular}

Partindo-se das capacidades destacadas no Quadro 2, propõe-se uma escala para a mensuração e validação de um construto específico para a identificação de capacidades turísticas desenvolvidas por empresas que atuam neste setor. Os procedimentos metodológicos utilizados para testar e validar o construto proposto nesta pesquisa são apresentados a seguir.

\section{Método e Procedimento da Pesquisa}

Buscando-se desenvolver e validar uma escala para a mensuração das capacidades turísticas das empresas que atuam neste setor, promoveu-se uma pesquisa exploratória e descritiva, a qual foi desenvolvida em três etapas. Inicialmente realizou-se uma pesquisa bibliográfica com o intuito de contextualizar o desenvolvimento de capacidades dinâmicas nas organizações, de modo a sustentar a definição proposta para o construto de capacidades turísticas apresentado nesta pesquisa. Nesta etapa da pesquisa, também procurou-se revisitar evidências de estudos anteriores que sugerem ações que podem estimular o desenvolvimento de capacidades turísticas mercadológicas, as quais podem contribuir para o desenvolvimento das organizações que atuam no setor turístico.

Tendo como base teórica as concepções acerca da temática turismo (KIRSTEN; ROGERSON, 2002; LUNDIE; DWYER; FORSYTH, 2007; ANDRADE; GOMES; XAVIER, 2010; MOTA; MACIEL FILHO, 2011; BOOYEN, 2012; GOH, 2012) e capacidades dinâmicas (COLLIS, 1994; TEECE; PISANO; SHUEN, 1997; DOSI; NELSON; WINTER, 2000; TEECE, 2009), foi desenvolvida a escala para mensuração do construto capacidade turística proposto nesta 
investigação. O construto elaborado foi categorizado em 5 variáveis (CT1 a CT5), sendo que cada uma possui um descritivo teórico, como demonstrado no Quadro 2. As variáveis formadoras deste construto são apresentadas no Quadro 3.

Quadro 3 - Indicadores de capacidade turística

\begin{tabular}{|c|c|c|c|}
\hline \multirow{6}{*}{ 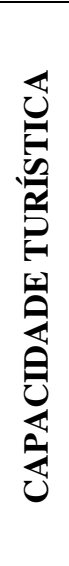 } & Variável & Indicador & $\begin{array}{l}\text { Evidências Teóricas } \\
\end{array}$ \\
\hline & CT1 & $\begin{array}{l}\text { Geração de atendimento personalizado } \\
\text { ao turista }\end{array}$ & $\begin{array}{l}\text { Kirsten e Rogerson (2002), Andrade, Gomes e } \\
\text { Xavier (2010) e Mota e Maciel Filho (2011) }\end{array}$ \\
\hline & $\mathrm{CT} 2$ & $\begin{array}{l}\text { Conhecimento sobre os atrativos } \\
\text { turísticos (locais) do município e } \\
\text { região }\end{array}$ & $\begin{array}{l}\text { Crouch e Ritchie (1999), Lundie, Dwyer e Forsyth } \\
\text { (2007) e Booyen (2012) }\end{array}$ \\
\hline & CT3 & $\begin{array}{c}\text { Atenção aos novos acontecimentos } \\
\text { turísticos (locais) no município e } \\
\text { região }\end{array}$ & $\begin{array}{l}\text { Crouch e Ritchie (1999), Lundie, Dwyer e Forsyth } \\
\text { (2007) e Booyen (2012) }\end{array}$ \\
\hline & CT4 & $\begin{array}{l}\text { Conhecimento sobre a história local e } \\
\text { regional }\end{array}$ & $\begin{array}{l}\text { Oliveira, Campomar e Luis (2008), Ferreira (2011) e } \\
\text { Perinotto e Santos (2011) }\end{array}$ \\
\hline & CT5 & $\begin{array}{l}\text { Localização próxima a pontos } \\
\text { estratégicos }\end{array}$ & $\begin{array}{l}\text { Bezerra (2006), Godinho e Oliveira (2010), Goh } \\
\text { (2012), Ivars I Baidal, Sánchez e Rebollo (2013) e } \\
\text { Pimentel e Carvalho (2014) }\end{array}$ \\
\hline
\end{tabular}

Definidos os indicadores de capacidade turística delimitados para este construto, a seguir desenvolveu-se a segunda etapa da pesquisa, em que promoveu-se uma investigação exploratória. A pesquisa exploratória foi desenvolvida a partir de um estudo de caso junto a uma organização hoteleira de grande porte, selecionada intencionalmente para a realização desta etapa da pesquisa. A partir de entrevista semiestruturada com o gerente administrativo desta empresa, procurou-se encontrar evidências que indiquem a confirmação das capacidades turísticas que conjuntamente compõe o construto teórico proposto nesta pesquisa.

De posse destas informações, a seguir procedeu-se a realização de uma pesquisa descritiva, realizada por meio de um levantamento com 65 hotéis que atuam com foco no turismo, localizados em diferentes regiões geográficas da cidade de São Paulo, os quais compõe a amostra investigada na pesquisa. Hair et al. (2009) ensina que este tipo de amostra é classificada como sendo por conveniência. A coleta de dados foi realizada por meio da aplicação de um questionário composto pelas cinco questões (indicadores) que compõe o construto de capacidade turística elaborado para a pesquisa. Para o levantamento dos dados, foi utilizada uma escala do tipo Likert de 1 a 7 pontos, em que a pontuação 1 foi atribuída à mínima intensidade nas ações e 7 à máxima intensidade na capacidade turística.

Os dados foram coletados pelos pesquisadores por telefone, junto aos gestores administrativos dos hotéis selecionados para a pesquisa. Inicialmente identificou-se a relação de empresas 
hoteleiras estabelecidas no Estado de São Paulo, associadas a ABIH-SP - Associação Brasileira da Indústria de Hotéis do Estado de São Paulo. Para tanto, acessou-se a relação de hotéis disponibilizada pela entidade em seu sítio.

De posse destas informações, procedeu-se o contato telefônico com alguns destes hotéis. Estabelecido o contato com as organizações contatadas, procurou-se conversar diretamente com o gerente administrativo do hotel ou gestor responsável, momento em que se procedeu a explicação dos objetivos da pesquisa e os propósitos do estudo. Em seguida, assegurou-se aos entrevistados que os dados seriam tratados de maneira consolidada, sem a identificação do respondente ou da organização participante da pesquisa. A partir do aceite do gestor entrevistado, procedeu-se o início da entrevista.

Tendo em vista as atividades dos hotéis, as ligações ocorreram em períodos variados e duraram em média entre $7 H_{23}$ minutos. Em alguns casos o gestor solicitou que a ligação fosse retornada em outro momento, sendo desconsiderada a primeira ligação na informação do tempo. Da mesma forma procedeu-se em relação ao período destinado a apresentação da pesquisa: i) informações sobre os pesquisadores; ii) objetivos/finalidade/confidencialidade; iii) tipo de questões; além de questionamentos sobre a mesma por parte dos respondentes. A coleta de dados foi realizada no período compreendido entre julho e agosto de 2014.

Os dados coletados foram tabulados em uma planilha eletrônica elaborada com o uso do software Excel 2010 e importados para análise estatística junto ao software PASW SPSS®, versão 18.0. A técnica estatística utilizada para a análise dos dados é a análise fatorial. Para a validação da escala proposta neste estudo, foram utilizados os seguintes indicadores estatísticos: i) comunalidades; ii) medida de adequação da amostra; iii) confiabilidade da amostra (alfa de Cronbach); iv) teste de esfericidade de Bartlett; v) correlação inter-itens; vi) correlação itemtotal; e; vii) carga fatorial. Estes procedimentos foram observados conforme as recomendações apresentadas por Hair Jr. et al. (2009). O Quadro 4 apresenta os indicadores utilizados para a validação do construto de capacidades turísticas e os valores mínimos esperados durante o tratamento dos dados. 
Quadro 4 - Medidas e valores mínimos esperados

\begin{tabular}{|l|c|}
\hline \multicolumn{1}{|c|}{ Medidas } & Valores Mínimos Esperados \\
\hline Comunalidades & 0,50 \\
\hline Medida de adequação da amostra (MSA) & 0,50 \\
\hline Confiabilidade da amostra (alfa de Cronbach) & 0,70 \\
\hline Teste de esfericidade de Bartlett & $\mathrm{p} \leq 0,05$ \\
\hline Correlação inter-itens & 0,30 \\
\hline Correlação item-total & 0,50 \\
\hline Carga fatorial (para $\mathrm{n}$ 60) & 0,70 \\
\hline
\end{tabular}

Fonte: elaborado a partir de Hair Jr. et al. (2009)

Considerando-se o total de variáveis (5) em função da amostra (65) alcançada nesta pesquisa, obteve-se um coeficiente de 13 observações por variável observada. Neste sentido, destaca-se que a amostra atende de maneira plena o que Hair Jr. et al. (2009) consideram adequado. Segundo os autores, para a validação de um determinado construto torna-se necessário alcançar o mínimo aceitável de 5 observações por indicador observado, sendo que o ideal seriam 10 observações para a execução da análise fatorial. Valor superior foi alcançado neste estudo. Os resultados da pesquisa são apresentados a seguir.

\section{Apresentação dos Resultados}

Este capítulo apresenta a análise dos dados, a qual está dividida em duas etapas. Inicialmente apresentam-se os resultados do estudo de caso realizado. A seguir, os resultados do levantamento realizado e da validação da escala de mensuração das capacidades turísticas elaborada para esta pesquisa.

\subsection{Análise do estudo de caso}

Nesta etapa da pesquisa procurou-se identificar junto ao gestor administrativo de uma organização hoteleira de grande porte, sua percepção em relação aos indicadores de capacidades turísticas propostos para este estudo (Quadro 3). Esta etapa da pesquisa foi realizada com o propósito de encontrar evidências que suportem o desenvolvimento de tais capacidades turísticas nestas organizações.

Inicialmente questionou-se o gestor entrevistado sobre a necessidade de "geração de atendimento personalizado ao turista" para a diferenciação competitiva das empresas hoteleiras. De acordo com o relato do gestor entrevistado: "os turistas possuem diferentes necessidades, [...] por isto personalizar o atendimento é uma forma de encantá-lo, atender necessidades 
específicas, [...] o que contribui para o seu retorno ao hotel". Da mesma forma, conforme explica o gestor, "as necessidades dos clientes são dinâmicas, [...] razão pela qual constantemente torna-se necessária a adaptação da nossa organização para que seja possível satisfazer e reter nossos clientes. [...] É dessa forma que conseguimos nos consolidar neste segmento".

Assim como preconizado por Andrade, Gomes e Xavier (2010), no turismo, a hospitalidade é algo esperado em qualquer atendimento prestado. A oferta de serviços personalizados, direcionados ao atendimento de necessidades específicas dos clientes contribui para a qualificação dos serviços prestados, um melhor atendimento (KIRSTEN; ROGERSON, 2002; MOTA; MACIEL FILHO, 2011) e a diferenciação competitiva das empresas que atuam neste setor. Portanto, organizações que prestam serviços personalizados tendem a desenvolver capacidades turísticas.

A seguir, questionou-se sobre a necessidade de "conhecimento sobre os atrativos turísticos (locais) do município e região", bem como de "atenção aos novos acontecimentos turísticos (locais) no município e região". Os relatos obtidos junto ao entrevistado revelam a importância de se conhecer adequadamente os atrativos turísticos locais. "Nossos clientes ao chegarem no hotel já possuem expectativas e demandas. [...] Vieram para nosso hotel por alguma motivação. [...] Por isto esperam receber informações objetivas, precisas, capazes de lhes direcionar aos locais desejados. [...] Frequentemente nós ouvimos relatos de experiências frustradas, em que os clientes não conseguiam obter as informações desejadas em outros hotéis. Isto atrasa sua programação, seus passeios, além de gerar custos adicionais ao turista. [...] Por estas razões, alguns de nossos clientes nos relataram que chegaram a trocar de hotéis por falta de informação adequada sobre atrativos turísticos locais e acontecimentos locais".

Da mesma forma, os relatos do gestor entrevistado revelam a importância de se atentar para os novos acontecimentos turísticos. Segundo o gestor, “[...] Além de estar atento as questões que acontecem em nossa cidade e na região, é necessitário se ter um conhecimento amplo sobre os atrativos turísticos presentes em nossa área de abrangência, [...] em toda a nossa área de atuação. Inclusive é importante se conhecer os atrativos que existem no Estado. [...] Em nossa organização, primamos pela excelência na qualidade informacional, no relacionamento com os clientes e na prestação de serviços. [...] Estar preparado e dar uma informação correta, adequada, hoje com certeza é um diferencial de qualquer organização hoteleira". 
Tais resultados são convergentes as reflexões promovidas por Kirsten e Rogerson (2002) e Lundie, Dwyer e Forsyth (2007). Clientes possuem potenciais diferentes e expectativas diferentes. Por esta razão, o desenvolvimento de um mix de serviços diversificado facilita a oferta de um conjunto maior de opções de serviços ao turista, o que pode estimular o seu consumo (KIRSTEN; ROGERSON, 2002) e contribuir para a sua satisfação e seu retorno. Neste sentido, a atratividade dos destinos turísticos é determinante para a satisfação dos clientes e seu retorno (CROUCH; RITCHIE, 1999). Uma vez que a informação é fundamental para a criação de valor aos serviços prestados no setor turístico (BOOYEN, 2012), a capacidade de uma empresa que atua neste setor em reconhecer e proporcionar aos turistas atrativos turísticos é imprescindível para a sua diferenciação. Portanto, organizações que desenvolvem conhecimentos sobre os atrativos turísticos locais (do município e região) e estão atentas a novos acontecimentos tendem a desenvolver capacidades turísticas.

Outro item questionado ao gestor entrevistado nesta etapa da pesquisa, versa sobre a necessidade de se "conhecer sobre a história local e regional". Os relatos obtidos revelam que aspectos históricos e sociais são relevantes para a retenção de clientes. Conforme relata o gestor, “Aspectos históricos locais estimulam o turismo e a curiosidade do turista. [...] Saber contar estas histórias e indicar os locais adequados aonde o turista pode visitar para reviver estes acontecimentos é um diferencial que estimula os turistas a consumirem os produtos desenvolvidos nesta região, o que estimula o turismo local e regional". Também observa-se que "o status social de estar na cidade ou na região é um atrativo para os turistas. [...] Por isto é importante conhecer bem os atrativos da cidade, da região, para que a gente consiga atender bem nossos clientes".

Convergente aos achados de Perinotto e Santos (2011), pode-se verificar que a curiosidade do turista estimula o consumo dos serviços turísticos, assim como o status social de ter estado em determinado local. Desta forma, a demanda por informações históricas é constante neste setor (PERINOTTO; SANTOS, 2011; BOOYEN, 2012). Assim sendo, para que se possa manter-se competitivo, torna-se necessário também conhecer aspectos históricos que podem contribuir para o atendimento as expectativas e necessidades dos clientes, estimulando o consumo de serviços (OLIVEIRA; CAMPOMAR; LUIS, 2008). Portanto, organizações que desenvolvem conhecimentos sobre a história local e regional tendem a desenvolver capacidades turísticas. 
Por fim, o último item questionado ao gestor refere-se à contribuição da "localização próxima a pontos estratégicos" na diferenciação competitiva das organizações que atuam no turismo. Os relatos do entrevistado revelam que "Os clientes procuram comodidade, facilidade de acesso, rapidez, serviços flexíveis [...]. O cliente hoje não quer passar trabalho. [...] Nossos clientes estão dispostos a pagar por isto, [...] estão dispostos a pagar para ter um pouco mais de conforto e comodidade. [...] Por isto, com certeza, a localização próxima a pontos estratégicos estimula o turismo".

Estes relatos são convergentes aos apontamentos encontrados na literatura de geografia e turismo. Estar bem posicionado geograficamente (BEZERRA, 2006; GODINHO; OLIVEIRA, 2010) e próximo a um ambiente com boa infraestrutura turística (GOH, 2012; IVARS I BAIDAL; SÁNCHEZ; REBOLLO, 2013; PIMENTEL; CARVALHO, 2014) estimula o desenvolvimento do turismo. Portanto, a localização próxima a pontos estratégicos contribui com as organizações que atuam neste setor para com o desenvolvimento de capacidades turísticas.

Como pode-se verificar, as evidências encontradas no estudo de caso realizado sugerem a validade dos indicadores de capacidade turística propostos nesta pesquisa. Uma vez que as empresas que atuam neste setor conseguem gerar atendimento personalizado ao turista, desenvolver conhecimentos sobre os atrativos turísticos (locais) do município e região, sobre a história local e regional, sobre os novos acontecimentos turísticos locais, bem como encontrar-se localizada próxima a pontos estratégicos, estas tendem a desenvolver suas capacidades dinâmicas, o que pela especificidade da atividade pode ser considerada uma capacidade turística. Logo, pode-se admitir que o desenvolvimento de capacidades turísticas contribui para o fortalecimento das organizações que atuam neste setor, a criação de valor e sua diferenciação competitiva. Neste contexto, diante das evidências encontradas, apresenta-se a proposição de uma escala para mensuração de capacidade turística, a qual passa a ser testada para sua validação como demonstrado a seguir.

\subsection{Testes de validação do construto de capacidades turísticas}

Nesta etapa da pesquisa efetuou-se os testes de validação estatística do construto de capacidades turísticas propostos para esta pesquisa. Para tanto, inicialmente efetuou-se um levantamento junto a gestores administrativos de 65 organizações hoteleiras que atuam com ênfase no turismo, 
em que foram efetuados cinco questionamentos relacionados aos indicadores de capacidades turísticas propostos para este estudo (Quadro 3).

De posse dos dados coletados, a seguir, promoveu-se os testes estatísticos para a validação da escala proposta neste estudo, utilizando-se da técnica de análise fatorial. Conforme recomendado por Hair Jr. et al. (2009), foram analisados os seguintes indicadores estatísticos: i) comunalidades; ii) medida de adequação da amostra; iii) confiabilidade da amostra (alfa de Cronbach); iv) teste de esfericidade de Bartlett; v) correlação inter-itens; vi) correlação itemtotal; e; vii) carga fatorial, procedimentos já especificados no capítulo metodológico desta pesquisa (Quadro 4).

A Tabela 1 evidencia os resultados dos testes realizados para a análise de comunalidades e as respectivas cargas fatoriais identificadas em cada indicador do construto capacidade turística.

Tabela 1 - Comunalidades e Carga Fatorial

\begin{tabular}{l|c|c|c|c|c|c}
\hline & & CT1 & CT2 & CT3 & CT4 & CT5 \\
\hline Comunalidades & & 0,708 & 0,529 & 0,739 & 0,535 & 0,587 \\
\hline Carga fatorial & & 0,841 & 0,727 & 0,860 & 0,731 & 0,766 \\
\hline Fonte:
\end{tabular}

Fonte: Dados da pesquisa

Em relação a análise de comunalidades, Hair Jr. et al. (2009) explicam que o valor mínimo aceitável deve ser de 0,500. Na análise dos resultados referentes as variáveis que formam o construto capacidade turística observa-se que o menor valor identificado foi de 0,529 (variável CT2), significando que, embora ela tenha menos em comum do que as outras variáveis, ainda participa com mais da metade da sua variância deste construto. Neste sentido, registra-se que todas as variáveis foram aprovadas no teste de comunalidade.

A carga fatorial identificada para cada uma das variáveis apresentou-se em valores superiores a 0,727. O valor mínimo foi registrado na variável CT2. Estes resultados refletem a correlação entre as variáveis que, segundo Hair Jr. et al. (2009), deve ser pelo menos 0,700 ou 0,650 para amostras de até 60 e 70 respondentes, respectivamente. Neste caso, em função da maior criticidade dos procedimentos adotados, utilizou-se como padrão o indicador de 0,700. Todas as cargas fatoriais ficaram acima do valor mínimo esperado, o que indica que os resultados em todos os indicadores do construto são aceitáveis. Portanto, constata-se que todas as variáveis, nos aspectos comunalidades e carga fatorial, estão em conformidade com o que expressa a literatura, validando-se assim, nestes testes, as variáveis mensuradoras do construto capacidade turística. 
A Tabela 2 apresenta os resultados encontradas na matriz anti-imagem da covariância e da correlação dos indicadores do construto.

Tabela 2 - Matriz Anti-imagem - (MSA)

\begin{tabular}{|c|c|c|c|c|c|c|}
\hline & & CT1 & CT2 & CT3 & CT4 & CT5 \\
\hline \multirow{5}{*}{$\begin{array}{c}\text { Anti-imagem } \\
\text { Covariância }\end{array}$} & CT1 & $\mathbf{0 , 3 8 9}$ & $-0,063$ & $-0,188$ & 0,018 & $-0,196$ \\
\hline & CT2 & $-0,063$ & $\mathbf{0 , 5 8 9}$ & $-0,088$ & $-0,246$ & 0,026 \\
\hline & CT3 & $-0,188$ & $-0,088$ & 0,408 & $-0,104$ & $-0,071$ \\
\hline & CT4 & 0,018 & $-0,246$ & $-0,104$ & $\mathbf{0 , 5 8 8}$ & $-0,075$ \\
\hline & CT5 & $-0,196$ & 0,026 & $-0,071$ & $-0,075$ & $\mathbf{0 , 5 2 9}$ \\
\hline \multirow{5}{*}{$\begin{array}{c}\text { Anti-imagem } \\
\text { Correlação }\end{array}$} & CT1 & $0,757^{a}$ & $-0,132$ & $-0,471$ & 0,038 & $-0,433$ \\
\hline & CT2 & $-0,132$ & $\mathbf{0 , 8 0 6 ^ { \mathrm { a } }}$ & $-0,179$ & $-0,417$ & 0,047 \\
\hline & CT3 & $-0,471$ & $-0,179$ & $0,811^{a}$ & $-0,212$ & $-0,152$ \\
\hline & CT4 & 0,038 & $-0,417$ & $-0,212$ & $0,799^{a}$ & $-0,135$ \\
\hline & CT5 & $-0,433$ & 0,047 & $-0,152$ & $-0,135$ & $0,821^{\circ}$ \\
\hline
\end{tabular}

a. Measures of Sampling Adequacy (MSA)

Fonte: Dados da pesquisa

De acordo com Fávero et al. (2009, p. 255) a matriz anti-imagem de covariância e de correlação “apresenta os valores negativos das covariâncias e das correlações parciais entre as variáveis. Tais valores estimam as correlações entre as variáveis que não decorrem de fatores comuns". Com relação a medida de aderência da amostra (MSA), identificada na diagonal da matriz antiimagem de correlação, dentre todas as variáveis analisadas o valor 0,757 foi o menor encontrado (CT1). Os demais indicadores estão acima ou muito próximo de 0,800, o que segundo Hair Jr. et al. (2009) representa que estes podem ser considerados admiráveis. Desta maneira, observa-se que todas as variáveis passaram por esta medida.

Na sequência, realizou-se a análise dos resultados do teste de esferecidade de Bartlett, que são apresentados na Tabela 3.

Tabela 3 - KMO e Teste de Bartlett

\begin{tabular}{l|l|l}
\hline Medida de adequação da amostra Kaiser-Meyer-Olkin & $\mathbf{0 , 7 9 7}$ \\
\hline Teste de esfericidade de Bartlet & Qui-quadrado aproximado & 133,181 \\
\hline GL $=10$ & Sig. & $\mathbf{0 , 0 0 0}$ \\
\hline Fonte: Dados da pesquisa &
\end{tabular}

Este procedimento resultou na significância de $0,000(0,000<0,050)$, o que indica, segundo Hair Jr. et al. (2009), que este resultado aponta para a existência de correlações suficientes entre as variáveis para que se possa continuar os testes de validação do construto. Neste sentido, ao se analisar a medida de adequação da amostra de Kaiser-Meyer-Oklin (KMO), a mesma identificada foi de 0,797, sendo superior ao valor mínimo aceitável (0,700). De acordo com Fávero et al. (2009), o KMO compara as correlações simples com as parciais observadas entre as 
variáveis, sendo que o resultado encontrado nesta pesquisa representa que a análise fatorial é média $(0,7 \mid-0,8)$, ou devido à proximidade do resultado, até mesmo boa $(0,8 \mid-0,9)$.

Portanto, com estes resultados, conforme observa-se na Tabela 3, as variáveis do construto capacidade turística apresentaram viabilidade estatística, o que permite a continuidade do processo de validação da escala de mensuração. Desta forma, na etapa seguinte, avaliam-se os resultados alcançados para o teste de confiabilidade do construto (Tabela 4).

Tabela 4 - Estatísticas de confiabilidade

\begin{tabular}{c|c|c}
\hline Alfa de Cronbach & Alfa de Cronbach baseado em itens padronizados & No. de itens \\
\hline $\mathbf{0 , 8 3 1}$ & $\mathbf{0 , 8 4 5}$ & $\mathbf{5}$ \\
\hline \multicolumn{2}{l}{ Fonte: Dados da pesquisa }
\end{tabular}

Após a realização do teste de confiabilidade estatística (Tabela 4), verificou-se que o alfa de cronbach do construto apresentou o resultado de 0,831 , sendo que o valor padronizado é de 0,845, para as cinco variáveis que compõem o construto em avaliação. Segundo Hair Jr. et al. (2009), para atestar a confiabilidade do teste o valor deverá ser igual ou superior a 0,700. Logo, pode-se considerar que o construto capacidade turística obteve também êxito neste teste, refletindo que existe consistência na escala inteira proposta nesta pesquisa. Na Tabela 5 são apresentados os resultados da análise da correlação inter-itens.

Tabela 5 - Correlação inter-itens

\begin{tabular}{c|c|c|c|c|c}
\hline & CT1 & CT2 & CT3 & CT4 & CT5 \\
\hline CT1 & 1,000 & 0,459 & 0,715 & 0,422 & 0,663 \\
\hline CT2 & 0,459 & 1,000 & 0,520 & 0,578 & 0,352 \\
\hline CT3 & 0,715 & 0,520 & 1,000 & 0,521 & 0,578 \\
\hline CT4 & 0,422 & 0,578 & 0,521 & 1,000 & 0,406 \\
\hline CT5 & 0,663 & 0,352 & 0,578 & 0,406 & 1,000 \\
\hline Fonte: Dados da pesquisa
\end{tabular}

Observa-se pelos resultados apresentados na Tabela 5 que o menor valor encontrado, 0,352, refere-se a correlação entre as variáveis CT2 e CT5, estando acima dos valores mínimos recomendados pela literatura para a validação do construto. Conforme explicam Hair Jr. et al. (2009), na análise das correlações inter-itens os valores alcançados para a validação do construto não devem ser inferiores a 0,300, sob pena de inviabilizar a análise do mesmo. Neste contexto, diante dos resultados encontrados (Tabela 5), pode-se aferir que todas as variáveis apresentam-se acima do valor mínimo esperado, o que sugere a validação do construto.

No que se refere a análise dos resultados da correlação item-total, os autores recomendam que estas, para serem consideradas adequadas, devem ser superiores a 0,500 (HAIR JR. et al., 2009). 
Neste sentido, visualiza-se na Tabela 6 que o menor valor encontrado na escala proposta foi de 0,599 (CT4). Portanto, estes valores encontram-se acima dos valores mínimos esperados.

Tabela 6 - Correlação item-total

\begin{tabular}{c|c|c|c|c|c}
\hline \multirow{2}{*}{$\begin{array}{c}\text { Correlação } \\
\text { item-total }\end{array}$} & CT1 & CT2 & CT3 & CT4 & CT5 \\
\cline { 2 - 6 } & 0,698 & 0,610 & 0,736 & 0,599 & 0,613 \\
\hline
\end{tabular}

Na última etapa da análise da validação da escala proposta para a mensuração da capacidade turística, procedeu-se a avaliação dos resultados da variância total explicada pelo construto. Os resultados desta análise são apresentados na Tabela 7.

Tabela 7 - Variância total explicada

\begin{tabular}{c|c|c|c}
\hline \multirow{2}{*}{ Componente } & \multicolumn{3}{|c}{ Autovalores iniciais } \\
\cline { 2 - 4 } & Total & \% de Variância & Total \\
\hline 1 & 3,097 & 61,947 & 61,947 \\
\hline
\end{tabular}

Extraction Method: Principal Component Analysis.

Fonte: Dados da pesquisa

Como pode-se verificar na Tabela 7 , em relação ao teste de variância total explicada das variáveis que compõem o construto capacidade turística, constata-se que o primeiro componente principal do construto é responsável por $61,947 \%$ da variância explicada, o que, de acordo com Hair Jr. et al. (2009), já é um indicativo que o fator representa adequadamente todas as variáveis do construto (a partir de $60 \%$ ).

Diante do exposto, a partir do conjunto de indicadores analisados, pode-se verificar que a escala para mensuração proposta para o construto capacidade turística apresentou ajuste adequado durante o processo de avaliação estatística a que foi sujeitado. Portanto, tendo em vista que os resultados encontrados refletem indicadores de índices acima do que preconiza a literatura especializada (HAIR JR. et al., 2009), pode-se concluir que o construto investigado nesta pesquisa é adequado para se avaliar capacidades turísticas, considerando-se o conjunto de indicadores propostos para a sua mensuração, avaliados neste estudo.

\section{Considerações Finais}

$\mathrm{Na}$ intenção de contribuir com as pesquisas na área de administração e turismo, em específico com estudos direcionados as capacidades dinâmicas das organizações, bem como com o processo de formulação das estratégias dos gestores de empresas com foco em turismo, este estudo objetivou desenvolver e validar uma escala para mensuração da capacidade turística das 
empresas que atuam neste segmento. Para tanto, pesquisa exploratória e descritiva foi realizada com 65 hotéis com foco no turismo, todos localizados em diferentes regiões da cidade de São Paulo.

As capacidades turísticas abordadas nesta pesquisa referem-se como a capacidade das organizações que atuam no setor turístico em gerenciar potencialidades internas da empresa com vistas a agregação de valor aos serviços prestados. Evidências encontradas na literatura sugerem que o desenvolvimento de capacidades dinâmicas contribui para a geração de vantagem competitiva (TEECE; PISANO, 1994). Nesta perspectiva, depreende-se que por meio do desenvolvimento de capacidades turísticas torna-se possível a diferenciação e o desenvolvimento de vantagens competitivas, bem como o fortalecimento das organizações.

Neste contexto, cinco capacidades turísticas foram investigadas nesta pesquisa, sendo estas: geração de atendimento personalizado ao turista; conhecimento sobre os atrativos turísticos (locais) do município e região; atenção aos novos acontecimentos turísticos (locais) no município e região; conhecimento sobre a história local e regional; e, localização próxima a pontos estratégicos. Os resultados encontrados a partir do estudo de caso realizado revelaram que tais capacidades podem atuar como determinantes para a diferenciação competitiva das empresas hoteleiras, o que é convergente aos achados encontrados na literatura.

A geração de atendimento personalizado ao turista favorece o atendimento as necessidades específicas de cada cliente, o que caracteriza-se como um diferencial para as empresas que atuam neste setor. Da mesma forma, favorece o desenvolvimento de um mix de serviços, o que pode estimular o consumo e contribuir para o alcance das expectativas dos clientes (KIRSTEN; ROGERSON, 2002). Nesta perspectiva, a hospitalidade (ANDRADE; GOMES; XAVIER, 2010) e o desenvolvimento de serviços personalizados (KIRSTEN; ROGERSON, 2002; MOTA; MACIEL FILHO, 2011) também contribuem para tal diferenciação.

Em face das diferentes expectativas e potenciais de consumo dos clientes que consomem serviços turísticos, torna-se necessário o desenvolvimento de um conhecimento específico sobre os acontecimentos e atrativos turísticos locais, bem como os aspectos históricos da região. No setor turístico, a informação é um elemento chave para a criação de valor (BOOYEN, 2012). Da mesma forma, a atratividade proporcionada pelos diferentes destinos turísticos oferecidos aos clientes é determinante para a sua satisfação e seu retorno (CROUCH; RITCHIE, 1999). Adicionalmente, a localização (BEZERRA, 2006; GODINHO; OLIVEIRA, 2010) e a 
infraestrutura turística (GOH, 2012; IVARS I BAIDAL; SÁNCHEZ; REBOLLO, 2013;

PIMENTEL; CARVALHO, 2014) também constituem-se elementos chaves para a criação de valor neste setor.

De maneira geral, entende-se que tais fatores atuam concomitantemente determinando a capacidade turística das empresas. Assim, a análise conjunta de tais indicadores compõe o construto de capacidade turística proposto nesta pesquisa. Os resultados dos testes estatísticos realizados corroboram para a validade do construto, o que abre perspectivas para a realização de novos estudos. A compreensão das capacidades turísticas desenvolvidas pelas empresas hoteleiras pode contribuir para o entendimento de fatores que favorecem a capacidade adaptativa destas empresas, considerando as características do ambiente dinâmico deste setor. Da mesma forma, pode fornecer evidências que permitam o entendimento de como estas empresas alcançam e sustentam vantagens competitivas, o que resulta em um novo campo de pesquisa para essa temática.

Considerando-se a atualidade e relevância do tema, bem como a escassez de estudos com esta abordagem, pode-se concluir que a temática proposta nesta investigação é atual e relevante e apresenta oportunidades que estimulam a realização de novos estudos com ênfase no desenvolvimento de capacidades turísticas de empresas que atuam neste setor. Da mesma forma, permite a investigação de como tais capacidades contribuem para o desenvolvimento de recursos estratégicos, a criação de vantagens competitivas sustentáveis, a melhoria de processos, a criação de inovação, bem como sua influência sobre o desempenho das empresas.

Desta forma, esta pesquisa contribui teoricamente com a indústria do turismo, na medida em que desenvolve, valida e apresenta um instrumento singular para avaliar a capacidade interna das organizações em responder as demandas ambientais. Pela ótica empírica, é oportunizado aos gestores e tomadores de decisões do segmento hoteleiro, um instrumento simples e com eficácia avalizada pela pesquisa realizada, para que as ações estratégicas possuam o foco no fortalecimento das competências internas da organização. Logo, o construto capacidade turística apresentado aqui oportuniza as organizações o desenvolvimento de ações com vistas a obtenção de vantagem competitiva em relação aos concorrentes, além de motivar um horizonte de pesquisas relacionadas as estratégias organizacionais da área de turismo.

Neste contexto, entende-se que a partir da criação de grupos de pesquisa, com ênfase nessa temática, torna-se possível a ampliação do conhecimento existente sobre o tema, bem como a 
consolidação da literatura científica já disponível relacionada ao tema capacidades dinâmicas aplicadas as organizações turísticas, assim como o desenvolvimento de uma literatura específica que aborde a temática capacidades turísticas.

Não obstante, registra-se que os dados aqui identificados devem ser tratados com a devida parcimônia, uma vez que se atêm a um cenário específico e um prisma da indústria do turismo. Por outro ângulo, este apontamento não desmerece a pesquisa realizada, visto que os indicadores estatísticos foram submetidos ao rigor recomendado pela literatura e aprovados, revelando um novo constructo teórico para investigar um tipo de capacidade específica (capacidade turística), conforme recomendado por Teece, Pisano e Shuen (1997), quando destacara a especificidade da teoria das capacidades dinâmicas.

Por fim, recomenda-se que as agendas de pesquisa dos cientistas interessados na temática considerem incluir nas análises da capacidade turística, outras variáveis como o desempenho e a capacidade inovativa das empresas, apreciando não somente o segmento hoteleiro, mas também os demais players da indústria do turismo. Outras pesquisas também podem ser desenvolvidas incluindo outros construtos teóricos de análise, como mediadores da relação entre capacidade turística e desempenho, tais como: orientação empreendedora, incerteza ambiental e munificência. Tais variáveis são sugeridas e apoiadas pela literatura de capacidades dinâmicas como importantes variáveis de investigação.

\section{Referências}

ANDRADE, K. A. F.; GOMES, G. A. T.; XAVIER, P. B. A Hospitalidade nos Serviços no Turismo na Cidade de Goiânia (GO) sob a Visão de Turistas Participantes do XXXI Congresso Brasileiro de Urologia em 2009. In: VII Seminário da Associação Nacional Pesquisa e Pós-Graduação em Turismo, 2010, São Paulo. Anais... São Paulo: Anptur, 2010.

AUGIER, M.; TEECE, D. J. Dynamic capabilities and the role of managers in business strategy and economic performance. Organization Science, v. 20, n. 20, p. 410-421, 2009.

BEZERRA, M. M. O. Estratégias de desenvolvimento do turismo: em busca de uma tipologia. Economia e Sociedade, v. 15, n. 2, p. 347-374, ago., 2006.

BOOYEN, I. Innovation in Tourism: a new focus for research and policy development in south Africa. Africa Insight, v. 42, n. 2, p. 112-126, 2012.

BRUNELlI, M. Q.; MACEDO-SOARES, T. D. L. A. Oportunidades e Ameaças na Indústria do Turismo: análise estratégica relacional do caso dos hotéis líderes da cidade do Rio de Janeiro. Turismo em Análise, v. 23, n. 1, p. 28-53, 2012.

COLLIS, D. J. Research note: how valuable are organizational capabilities? Strategic Management Journal, v. 15, p. 143-152, 1994. 
COSMINA-SIMONA, T.; IOAN, B.; TABITA-CORNELIA, H.; REMUS, G. the need of management for Banat's tourism. Agricultural Management/Lucrari Stiintific, v. 15, n. 4, p. 247-250, 2013.

CROUCH, G. I.; RITCHIE, J. R. B. Tourism, competitiveness, and societal prosperity. Journal of Business Research, v. p. 44, 137-152, 1999.

DOSI, G.; NELSON, R. R.; WINTER, S. G. Introduction: The Nature and Dynamics of Organisational Capabilities. In.: DOSI, G.; NELSON, R. R.; WINTER, S. G. (Edt). The Nature and Dynamics of Organisational Capabilities. Oxford University Press: Oxford, 2000.

EINSENHARDT, K. M.; MARTIN, J. A. Dynamic capabilities: what are they? Strategic Management Journal, n. 21, p. 1105-1121, 2000.

ESCOBAR, M. A. R. Relação das capacidades dinâmicas e orientação empreendedora com o desempenho em agências de viagens moderada pelo ambiente organizacional. 2012. Tese (Doutorado em Administração), Programa de Pós-Graduação em Administração, UNIVALI, Biguaçu, SC, 2012.

FÁVERO, L. P.; BELFIORE, P.; SILVA, F. L.; CHAN, B. L. Análise de dados: modelagem multivariada para tomada de decisões. Rio de Janeiro: Elsevier, 2009.

FERREIRA, R. C. Lazer e potencialidades para o turismo em Piracuruca, Piauí. 2011. 170f. Dissertação (Mestrado em Desenvolvimento e Meio Ambiente) - Programa Regional de Pós-Graduação em Desenvolvimento e Meio Ambiente, Universidade Federal do Piauí, Teresina, 2011.

GARCÍA, P. J. C. Crecimento turístico versus desarrollo econômico. Un análisis desde la perspectiva de la generación de divisas y la capacidad de recaudación. Revista de Economía Mundial, v. 32, p. 73-102, 2012.

GODINHO, R. G.; OLIVEIRA, I. J. Análise e avaliação da distribuição geográfica da infraestrutura turística no sítio histórico de Pirenópolis (GO): subsídios ao planejamento turístico. Boletim Goiano de Geografia, v. 30, n. 1, p. 107-122, jan./jun. 2010.

GOH, C. Exploring Impact of Climate on Tourism Demand. Annals of Tourism Research, v. 4, n. 39, p.1859-1883, 2012.

GONZÁLES, J. A. M. La gestión de la empresa turística centrada en el residente: el caso de la generación Y. Revista de Investigación en Turismo y Desarrollo Local, v. 6, n. 15, p. 1-17, 2013.

HAIR, J. F. JR.; ANDERSON R. E.; TATHAM, R. L; BLACK, W. C. Análise multivariada de dados. 6. ed. Porto Alegre: Bookman, 2009.

IVARS I BAIDAL, J. A.; SÁNCHEZ, I. R., REBOLLO, J. F. V. The evolution of mass tourism destinations: New approaches beyond deterministic models in Benidorm (Spain). Tourism Management, n. 34, p. 184-195, 2013.

JIANG, L.; SU, Q.; DU, Z. A review and reflection of research on the sociocultural impacts of tourism since the $21^{\text {st }}$ century. Tourism Tribune, v. 28, n. 12, p. 1-4, 2013.

KASIM, A. The need for business environmental and social responsibility in the tourism industry. International Journal of Hospitality \& Tourism Administration, v. 7, n. 1, p. 1-22, 2006.

KIROVSKA, Z. Strategic management within the tourism and the world globalization. UTMS Journal of Economics, v. 2, n. 1, p. 69-76, 2011.

KIRSTEN, M.; ROGERSON, C. M. Tourism, business linkages and small enterprise development in South Africa. Development Southern Africa, v. 19, n. 1, 29-59, 2002.

LUNDIE, S.; DWYER, L.; FORSYTH, P. Environmental-economic measures of tourism yield. Journal of Sustainable Tourism, v. 15, n. 5, p. 503-519, 2007. 
MARANHÃO, R. A.; TEIXEIRA, C. E. Capacidades dinâmicas e sistema de gestão ambiental em organização militar da marinha do Brasil. Revista Ibero-Americana de Estratégia - RIAE, v. 14, n. 2, p. 121-136, 2015

MARTINS, E. S.; ROSSETO, C. R.; LIMA, N. C.; PENEDO, A. S. T. Comportamento estratégico e ambidestria: um estudo aplicado junto às empresas vinícolas brasileiras. Revista Brasileira de Gestão de Negócios, v. 16, n. 52, p. 392-415, 2014.

MEIRA, J. V. de S.; ANJOS, S. J. D. dos. Competitividade e desempenho: uma análise dos processos das redes hoteleiras. In: VII Seminário da Associação Nacional Pesquisa e Pós-Graduação em Turismo, 2014, Ceará. Anais... Fortaleza: Anptur, 2014.

MENEZES, P. D. L. Gestão turística e questões culturais. Turismo - Visão e Ação, v. 6, n. 1, p. 115-127, 2004.

MOLNAR, E.; STANCIULESCU, G. C. What future for tourism in the cold region environments? Annals of Faculty of Economics, v. 1, n. 1, p. 268-275, 2011.

MONDO, T. S.; FIATES, G. G. S. Qualidade de serviços em atrativos turísticos: um estudo da percepção dos turistas de Florianópolis - SC - Brasil. Revista Turismo em Análise, v. 26, n. 1, p. 112-137, 2015.

MOTA, K. C. N.; MACIEL FILHO, J. A. C. L. Segmento do turismo de negócios para as agências de viagem: perfil de clientes corporativos de Fortaleza e região metropolitana - CE. Turismo em Análise, v. 22 , n. 2, p. 428-444, 2011

NELSON, R. R. Why do firms differ, and how does it matter? Strategic Management Journal, v. 12, p. 61-74, 1991.

OLIVEIRA, B.; CAMPOMAR, M. C.; LUIS, C. Posicionamento estratégico em turismo: o caso Sabre Brasil. Turismo em Análise, v. 19, n.1, p. 64-84, 2008.

ORGANIZAÇÃO MUNDIAL DO TURISMO (OMT). UNWTO Annual Report 2013. UNTWO, 2014.

PANSIRI, J. Strategic motives for alliance formation in the travel sector of tourism. International Journal of Hospitality and Tourism Administration, v. 10, n. 2, p. 143-173, 2009.

PERINOTTO, A. R. C.; SANTOS, A. K. P.. Patrimônio cultural e turismo: um estudo de caso sobre a relação entre a população parnaibana e o complexo Porto das Barcas. Revista Brasileira de Pesquisa em Turismo, v.5, n. 2, p. 201-225, 2011.

PEZZI, E.; VIANNA, S. L. G. A experiência turística e o turismo de experiência: um estudo sobre as dimensões da experiência memorável. Revista Turismo em Análise, v. 26, n. 1, p. 165-187, 2015.

PIMENTEL, T. D.; CARVALHO, F. C. C. Fatores condicionantes do planejamento e gestão em destinos turísticos: um quadro teórico de análise. Revista de Investigación en Turismo y Desarrollo Local, v. 7, n. 16, p. 2-38, jun./jun., 2014.

RAMGULAM, N.; RAGHUNANDAN, M.; RAGHUNANDAN, M. The quest for sustainable business tourism: an examination of its economic viability in Trinidad. Global Conference On Business \& Finance Proceedings, v. 7, n. 2, p. 331-342, 2012.

ROXANA, S.; ANAMARIA, P.; CORINA, G. Effects of customer orientation, learning orientation and innovativeness on hotel performance - evidence from Cluj County. Economic Science Series, v. 22, n. 1, p. $807-814,2013$.

SILVEIRA-MARTINS, E.; TAVARES, P. M. Processo de formulação de estratégias: capacidade mercadológica, incerteza ambiental e desempenho. Revista Organizações em Contexto, v. 10, n. 20, p. 297-322, 2014.

TEECE, D. J. Dynamic capabilities \& strategic management. Oxford: Oxford University Press, 2009. 
TEECE, D. J.; PISANO, G.; SHUEN, A. Dynamic Capabilities and Strategic Management. Strategic Management Journal, v. 18, n. 7, p. 509-533, 1997.

TEECE, D.; ADBULRAHMAN, Y. A. A. Knowledge, entrepreneurship, and capabilities: revisiting the theory of the MNE. Universia Business Review, n. 40, p. 18-32, 2013.

TEECE, D.; PISANO, G. The dynamic capabilities of firms: an introduction. Industrial and Corporate Change, v. 3, n. 3, p. 537-556, 1994.

ZONATTO, V. C. S.; SCHUH, C.; ZONATTO, P. A. F. Contribuição dos Recursos Estratégicos nos Processos de Criação da Inovação em uma Rede de Cooperação Hoteleira. Revista Turismo em Análise, v. 25, n. 3, p. 700-732, 2014.

Recebido em: 20/04/2015 ( $1^{\mathrm{a}}$ versão) $18 / 12 / 2015$ ( $2^{\mathrm{a}}$ versão $)$

Aprovado em: 21/12/2015 